\title{
The prevalence of impaired glucose counter-regulation during an insulin-infusion test in insulin-treated diabetic patients prone to severe hypoglycaemia
}

\author{
N.Clausen Sjöbom, U.Adamson and P.-E. Lins \\ Department of Internal Medicine, Danderyd Hospital, Danderyd, Sweden
}

\begin{abstract}
Summary. Among 603 patients over the age of 18 , with insulin-treated diabetes mellitus, a questionnaire identified 98 patients who during a 12 -month period had experienced severe hypoglycaemia, defined as an event which required the help of another person. Twenty of these patients had repeatedly suffered from such episodes, without any obvious reason, for a period of at least three years. The capacity to counter-regulate a standardized, insulin-infusion test $\left(0.034 \mathrm{U} \cdot \mathrm{kg}^{-1} \cdot \mathrm{h}^{-1}\right.$ given for $3 \mathrm{~h}$ unless severe neuroglucopenia developed) was evaluated in 14 of these patients. In 12, an impaired glucose counter-regulation was registered, defined as blood-glucose values below -2 SD of healthy subjects. In all but one of these patients, a combined deficiency of glucagon and adrenaline was documented, and was believed to be the likely cause of their inclination towards hypoglycaemia. In
\end{abstract}

patients with severe hypoglycaemia, but not in diabetic patients without severe hypoglycaemia or in healthy subjects, a significant relationship between insulin disappearance and glucose rise was found. It is concluded that in insulin-treated diabetic patients, the prevalence of recurrent attacks of severe hypoglycaemia amounts to about $4 \%$. In such patients, a combined deficiency of adrenaline and glucagon responses to hypoglycaemia is the predominant finding and the disappearance rate of insulin becomes critical for recovery of blood glucose after hypoglycaemia.

Key words: Insulin-treated diabetes mellitus, recurrent hypoglycaemia, insulin-infusion test, adrenaline, glucagon, growth hormone, cortisol, metabolic clearance rate for insulin, insulin-binding antibodies.
Hypoglycaemic episodes are troublesome for patients with insulin-treated diabetes mellitus. In a small group of such patients, recurrent attacks of severe hypoglycaemia is a predominant problem. There are a number of well-established reasons which may explain why diabetic patients run into severe hypoglycaemic episodes. Poor patient compliance with injection technique, inappropriate insulin-dosing with respect to meals and physical activity, a recent change of insulin dose and alcohol intake [1-2] are factors known to precipitate hypoglycaemia.

Other well-known aetiological factors to consider are severe liver or kidney disease [3], pituitary or adrenal insufficiency [4-5] and primary hypothyroidism [6-7]. Impairment of the responses of counter-regulatory hormones to hypoglycaemia has also been associated with severe hypoglycaemia [8-11]. Finally, altered pharmaco-kinetics of insulin have been demonstrated in diabetic patients with insulin-binding antibodies and have been proposed to increase the risk of hypoglycaemia [9, 12-13]. However, in a recent investigation, no correlation between high levels of insulin-binding to anti- bodies and severe hypoglycaemia, could be documented [14].

The aims of the present study were to analyse the prevalence of recurrent, severe hypoglycaemia in the insulin-treated diabetic patients resident in the area covered by our clinic, and to assess the glycaemic and hormonal responses to an insulin-infusion test, as well as the metabolic clearance rates (MCR) for i.v. infused insulin.

\section{Subjects and methods}

\section{Subjects}

Danderyd Hospital is situated in the Greater Stockholm area, serving a population of about 192,000 adult inhabitants. During 1984,603 patients with diabetes mellitus on insulin therapy were registered in our out-patient clinic. Based on clinical criteria we estimate that $71 \%$ of these were insulin-dependent, thereby comprising about $90 \%$ of the insulin-dependent diabetic patients resident in our area. A questionnaire, which was answered by $90 \%$, identified 98 patients who, during a 12-month-period, had experienced at least one severe hypogly- 
Table 1. Characteristics of the diabetic patients with and without severe hypoglycaemia (SH)

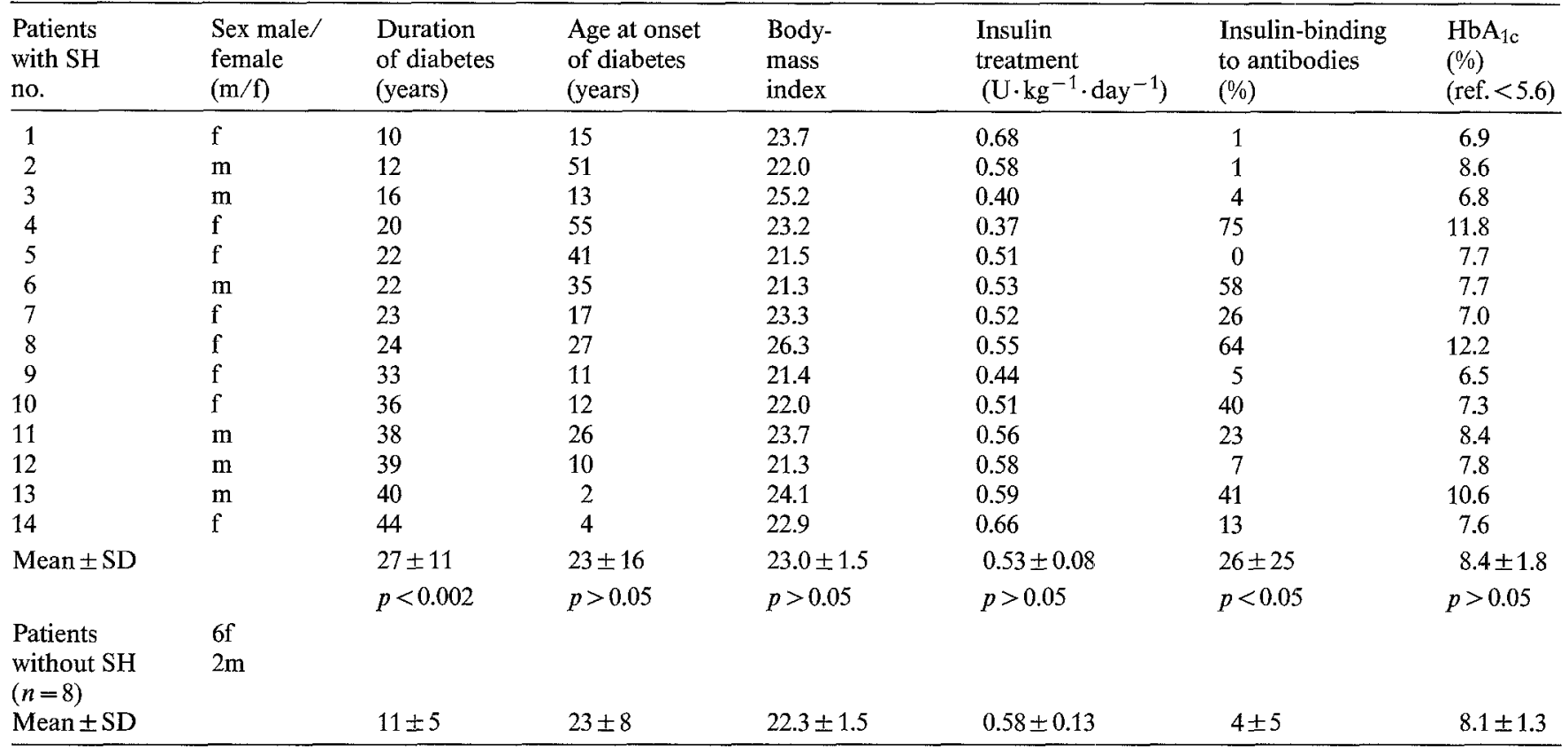

Table 2. Late diabetic complications in diabetic patients with and without severe hypoglycaemia (SH)

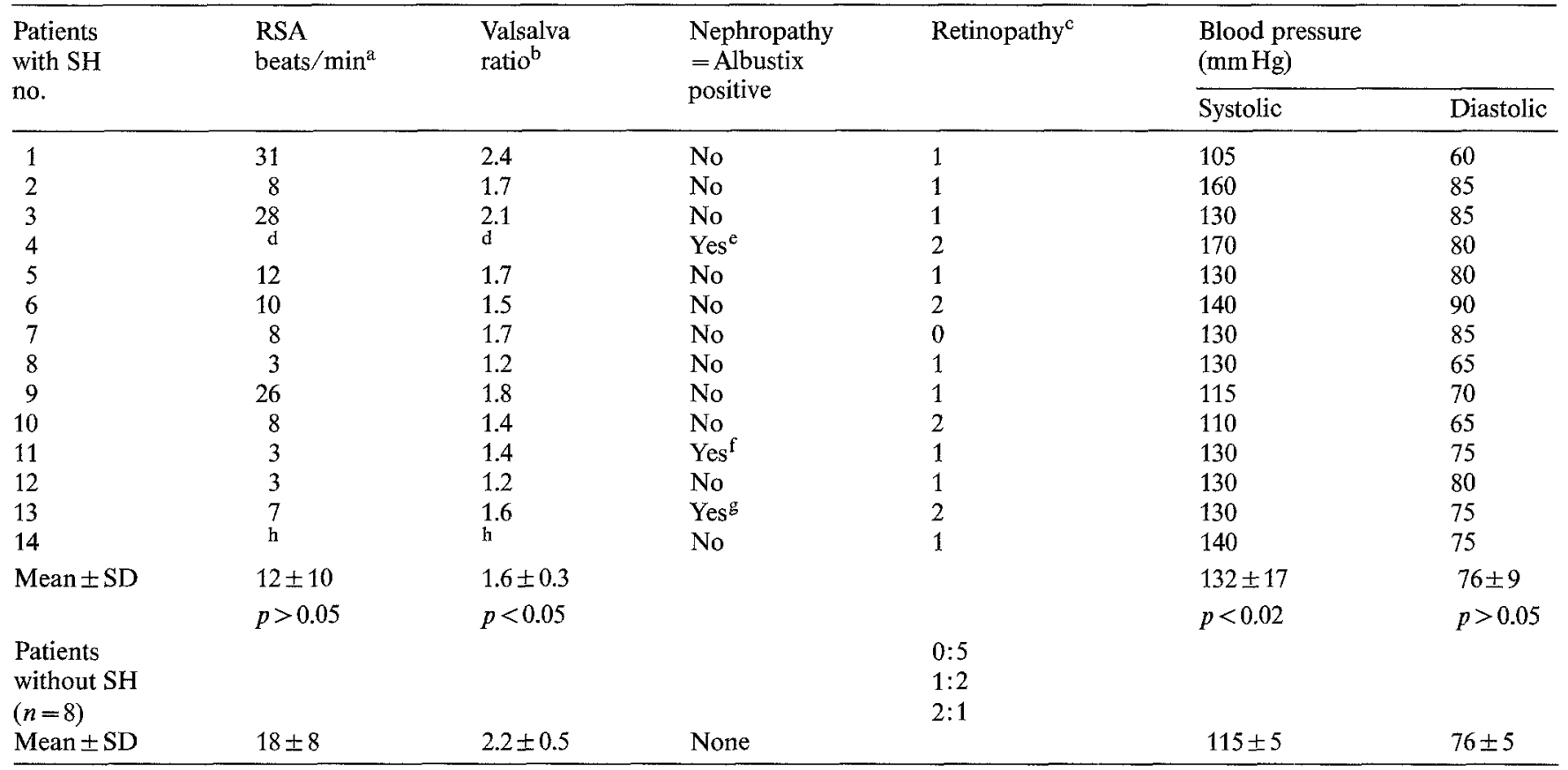

a $\mathrm{RSA}=$ Respiratory sinus arrhythmia, ref. $\geq 9$ beats $/ \mathrm{min} ;{ }^{\mathrm{b}}$ Ref. $\geq 1.5 ;{ }^{\mathrm{c}}$ Fundoscopic examination by ophthalmologist, $0=$ none, $1=$ non-proliferative, $2=$ proliferative; ${ }^{\mathrm{d}}$ Not cooperative/not willing to participate; ${ }^{\mathrm{e}}$ Constant Albustix positive, $s$-creatinine $150 \mu \mathrm{mol} / \mathrm{l}$ (ref. females $<100$ ); ${ }^{\mathrm{f}}$ Constant Albustix positive, $s$-creatinine $135 \mu \mathrm{mol} / 1$ (ref. males $<110$ ); $\mathrm{g}$ Intermittent Albustix positive; h Previous thoracic surgery

caemic event, defined as a hypoglycaemia for which the treatment required the help of another person. A detailed analysis revealed that 20 of these patients had suffered from severe, hypoglycaemic episodes over three years or more, without any obvious reason. Male and female subjects were almost equally affected. Ten subjects had been on insulin therapy for more than 30 years, and only four had a duration of the disease of less than 20 years. No patient was markedly obese or underweight. Their 24-h insulin dose varied between 0.37 and $0.68 \mathrm{U} \cdot \mathrm{kg}^{-1}$ and short-acting insulin amounted to $37 \pm 22 \%$ of the total daily dose. At the time of the investigation, insulin was given as one daily injection in one patient, as two daily injections in ten and as 3-4 daily doses in eight patients. One patient used an insulin pump. After initiation of insulin pump therapy, the frequency of hypoglycaemic episodes had markedly decreased. Plasma C-peptide above the detection limit was demonstrable in one patient, who displayed a postprandial, plasma C-peptide value of $0.38 \mathrm{nmol} / 1$. Antibodies against adrenocortical cytoplasmic antigen were not registered in any of the patients and conventional blood tests did not disclose evidence 
Glucose (mmol/l)

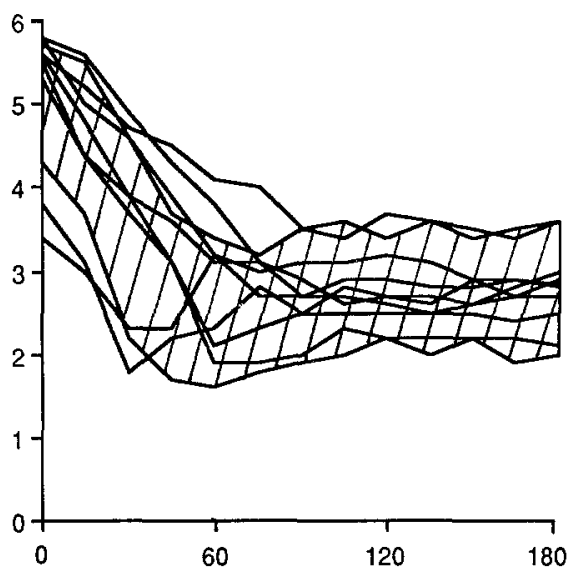

Glucose (mmol/)

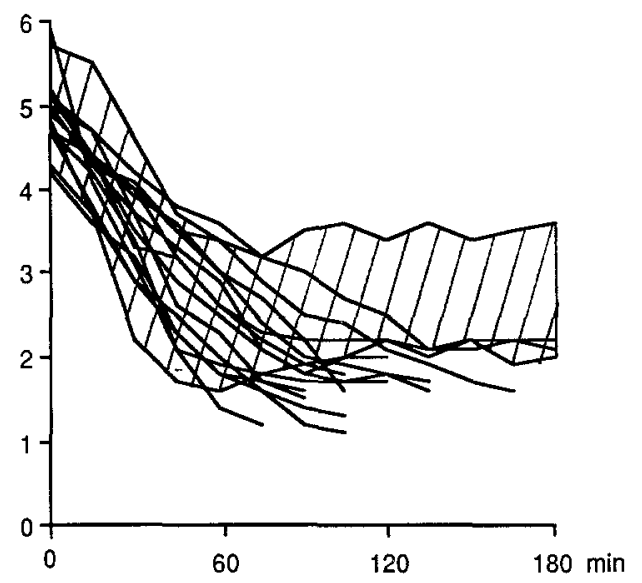

Fig. 1. Individual blood glucose curves for diabetic patients without severe hypoglycaemia $(n=8)$ (left) and with severe hypoglycaemia $(n=14)$ (right). Shaded area indicates mean \pm 2 SD of the healthy subjects $(n=8)$ of hepatic dysfunction. Two patients were given thyroxine because of primary hypothyroidism and were euthyroid. One patient was treated with metoprolol due to hypertension.

Of these 20 patients, 14 could be further examined and will be referred to as the severe hypoglycaemia ( $\mathrm{SH}$ ) patient group. Relevant clinical data of these patients are given in Table 1 and information on late diabetic complications and autonomic nervous functions as assessed by the respiratory sinus arrhythmia [15] and the Valsalva ratio [16] is presented in Table 2. Albuminuria was determined by Albustix (Ames Division, Slough, UK) where positive is defined as more than $0.3 \mathrm{~g} / 1$.

For comparison, we invited eight healthy subjects (six women and two men, age $48 \pm 10$ years, body mass index $23.4 \pm 3.4$ ) and eight insulin-treated, diabetic patients (non-SH group) with no measurable, postprandial, plasma C-peptide levels, to participate in the same experimental procedures. These diabetic patients were selected from our out-patient clinic, as they did not report severe hypoglycaemic attacks in the above-mentioned questionnaire. Furthermore, they did not have any evidence of autonomic neuropathy. Only subjects with a level of insulin-binding to antibodies below $10 \%$ were considered. Some clinical characteristics of the non-SH group have been included in Tables 1 and 2, respectively. One patient was treated with two daily doses of insulin, six patients with 3-4 daily injections and one used an insulin pump. Their mean insulin dose was $0.58 \pm 0.13 \mathrm{U} \cdot \mathrm{kg}^{-1}$. $\mathrm{day}^{-1}$ and of the total daily insulin dose $57 \pm 21 \%$ was short-acting. This amount was significantly higher $(p<0.05)$ when compared to the 20 patients who reported severe hypoglycaemia.

All subjects gave their informed consent to the study which was approved by the local ethical committee.

\section{Protocols}

All subjects were exposed to an i.v. insulin-infusion test. In the diabetic patients, no intermediate-acting insulin was given $36 \mathrm{~h}$ prior to the test, and their s.c. injections of short-acting insulin were replaced by a variable, i.v., insulin infusion $24 \mathrm{~h}$ before the start, in order to deplete the subcutaneous insulin depots. The variable i.v. insulin infusion preceding the insulin-infusion test intended to keep the blood glucose between 6 and $12 \mathrm{mmol} / \mathrm{l}$. The patients had their regular meals on the day before the test, but no food was ingested after 22.00 hours. The healthy subjects reported to the ward in the morning after an overnight fast. At 08.00 hours on the day of the study, a constant-rate, i.v. insulin infusion was started $\left(0.034 \mathrm{U} \cdot \mathrm{kg}^{-1} \cdot \mathrm{h}^{-1}, \mathrm{Ac}-\right.$ trapid, NOVO Company A/S, Copenhagen, Denmark) and continued for $3 \mathrm{~h}$, unless the subjects displayed signs of neuroglucopoenia by the inability to perform simple mathematical calculations, in which case the insulin infusion was stopped. After cessation of the insulin infusion, blood glucose and free insulin levels were monitored at $10 \mathrm{~min}$ intervals for another $60 \mathrm{~min}$, in order to register the spontaneous capacity of each subject's restitution of their blood glucose from the hypoglycaemic range and to eliminate insulin from the circulation. Venous blood samples for immediate analysis of blood glucose were taken every $15 \mathrm{~min}$ and venous blood samples were drawn for the later analysis of plasma free insulin, glucagon, growth hormone, cortisol, adrenaline and noradrenaline at 30 -min intervals.

\section{Assays}

$\mathrm{HbA}_{1 \mathrm{c}}$ was measured by a liquid-chromatographic assay (normal level $<5.6 \%$ ) [17]. Analysis of insulin-binding to antibodies was performed by a combined polyethylene glycol and anti-IgG precipitation method formulated by NOVO Company A/S. The intra-assay coefficient of variation for the method was 3.8\% [18]. Blood samples for the analysis of plasma C-peptide (normal range $0.18-0.63 \mathrm{nmol} / \mathrm{l}$ ) were taken in the fasting state, and $2 \mathrm{~h}$ after a standardized meal, in order to evaluate the endogenous insulin secretion [19]. Blood glucose was measured by a glucose analyser (Model 23 A.M., Yellow Springs Instruments, Yellow Springs, Ohio, USA). Plasma free insulin [18], glucagon [20], growth hormone [21] and cortisol [22] were determined by radioimmunoassay techniques. The blood samples taken for the analysis of plasma free insulin were immediately treated with polyethylene glycol prior to centrifugation. Adrenaline and noradrenaline were analysed by liquid chromatography with electrochemical detection [23].

\section{Statistical analysis}

The MCR for insulin was calculated as the ratio between the constant insulin-infusion rate $\left(\mu \mathrm{U} \cdot \mathrm{m}^{2-1} \cdot \mathrm{min}^{-1}\right)$ and the steady-state, plasma free insulin concentration $\left(\mu \mathrm{U} \cdot \mathrm{ml}^{-1}\right)$. Appearance of blood glucose and disappearance of plasma free insulin were calculated according to the formula of $\ln 2 / t_{1 / 2}$ (where $\ln 2$ is the natural logarithm for $2=0.693$ ) and expressed as $k$-values.

The Mann-Whitney two-tailed U-test for independent samples was applied in the statistical evaluation. Unless otherwise indicated all values are presented as mean $\pm \mathrm{SD}$.

\section{Results}

In the healthy subjects, the i.v. insulin infusion raised the mean plasma free insulin level to about $40 \mathrm{mU} / 1$, corresponding to a MCR for insulin of $578 \pm 52 \mathrm{ml}$. 
Table 3. Blood glucose values and corresponding hormonal levels at the cessation of insulin infusion in the diabetic patients with severe hypoglycaemia $(\mathrm{SH})$

\begin{tabular}{|c|c|c|c|c|c|c|c|c|c|}
\hline \multirow{2}{*}{$\begin{array}{l}\text { Patients } \\
\text { with SH } \\
\text { no. } \\
1\end{array}$} & \multirow{2}{*}{$\begin{array}{l}\text { Blood glucose } \\
\text { (mmol/1) } \\
\text { At cessation } \\
1.8\end{array}$} & \multicolumn{2}{|c|}{$\begin{array}{l}\text { Adrenaline } \\
(\mathrm{nmol} / \mathrm{l}) \\
\text { At cessation } \Delta^{\mathrm{a}}\end{array}$} & \multicolumn{2}{|c|}{$\begin{array}{l}\text { Glucagon } \\
\text { (ng/ } /) \\
\text { At cessation } \Delta^{\mathrm{a}}\end{array}$} & \multicolumn{2}{|c|}{$\begin{array}{l}\text { Growth hormone } \\
\text { (pmol/l) } \\
\text { At cessation } \Delta^{\mathrm{a}}\end{array}$} & \multicolumn{2}{|c|}{$\begin{array}{l}\text { Cortisol } \\
(\text { nmol/1) } \\
\text { At cessation } \Delta^{\mathrm{a}}\end{array}$} \\
\hline & & 0.4 & +0.3 & 61 & -21 & 1932 & +1776 & 279 & -78 \\
\hline 3 & 1.7 & 2.1 & +2.1 & 416 & +200 & 3404 & +3400 & 921 & +357 \\
\hline 4 & 1.7 & 0.2 & +0.2 & 159 & +21 & 1242 & +1148 & 332 & -125 \\
\hline 5 & 1.6 & 1.9 & +1.7 & $<50$ & 0 & 106 & -446 & 535 & +153 \\
\hline 8 & 1.4 & 4.9 & +4.8 & 214 & +20 & 414 & +414 & 753 & +42 \\
\hline 9 & 1.2 & 1.5 & +1.3 & 265 & +172 & 345 & -69 & 346 & +64 \\
\hline 10 & 2.0 & 1.5 & +1.5 & 179 & -5 & 920 & +898 & 506 & +130 \\
\hline 11 & 1.7 & 0.3 & +0.3 & 265 & +42 & 2668 & +2454 & 383 & +31 \\
\hline 12 & 1.7 & 1.1 & +1.1 & 185 & +6 & 2116 & +2105 & 402 & +41 \\
\hline 13 & 2.2 & 2.1 & +2.0 & 413 & +225 & 2622 & +2252 & 810 & +460 \\
\hline
\end{tabular}

a $\Delta$-values are calculated as the level at the cessation of insulin infusion, minus the level at the start of the insulin-infusion test.

$\mathrm{m}^{2-1} \cdot \min ^{-1}$ which resulted in a decline of blood glucose over the first h, after which the blood glucose reached an apparent, steady-state level with a mean of $2.8 \mathrm{mmol} / 1$ (Fig. 1). Neuroglucopenic signs, necessitating cessation of the insulin infusion, did not develop in any non-diabetic subject. After the termination of the insulin infusion, the plasma-insulin levels fell rapidly in parallel with a gradual rise in blood-glucose concentrations reaching a blood glucose of $4.3 \pm 0.5 \mathrm{mmol} / 1$ after $60 \mathrm{~min}$.

In the non-SH group insulin levels were lower than in the healthy subjects $(-30 \mathrm{mU} / \mathrm{l})$ with a corresponding MCR for insulin of $762 \pm 166 \mathrm{ml} \cdot \mathrm{m}^{2-1} \cdot \mathrm{min}^{-1}$ $(p<0.02)$. All patients in this group attained steady state blood glucose levels within \pm 2 SD of the healthy subjects (Fig.1) and neuroglucopenic signs necessitating cessation of the insulin infusion did not appear. The recovery of blood glucose following the cessation of the insulin infusion was similar to that of healthy subjects, reaching the normal range or above within $60 \mathrm{~min}$, yielding a blood glucose of $5.5 \pm 0.7 \mathrm{mmol} / \mathrm{l}$.

During the insulin-infusion test the SH-group attained plasma levels of insulin which were similar to those of the non-SH group with the exception of patient no. 8 who displayed plasma insulin levels of about $60 \mathrm{mU} / 1$ and a MCR for insulin of $390 \mathrm{ml} \cdot \mathrm{m}^{2-1}$. $\mathrm{min}^{-1}$. In this patient, the insulin-infusion test had to be stopped at a blood glucose of $1.4 \mathrm{mmol} / 1$ after $90 \mathrm{~min}$. Because of her abnormal pharmacokinetics of insulin this patient will be considered separately.

When the MCR for insulin was calculated in the remaining 13 patients of the SH-group, a value of $755 \pm 117 \mathrm{ml} \cdot \mathrm{m}^{2-1} \cdot \mathrm{min}^{-1}$ was obtained, which was significantly higher than that of healthy subjects $(p<0.002)$ but not different from the non-SH group $(p>0.05)$. We found no correlation $(r=0.19)$ between the MCR value for insulin and the corresponding insulin-binding to antibodies presented in Table 1 . Two patients of the SH-group displayed blood-glucose values within the mean $\pm \mathrm{SD}$ of the healthy subjects over the whole 3 -h insulin-infusion period, while, in the rest of the patients, the insulin infusion resulted in blood glucose values below this range between 75 and $165 \mathrm{~min}$ from the onset of the experiment (Fig. 1). The nadir blood glucose values obtained in these patients are illustrated in Table 3. Neuroglucopenic signs developed in these patients necessitating cessation of the experiment. Restitution of blood glucose was impaired in the SH-group of patients as compared with the non$\mathrm{SH}$ group $(p<0.02)$.

$K$-values for insulin disappearance were $1.41 \pm 0.28 \mathrm{~h}^{-1}$ in healthy subjects, $2.80 \pm 1.80 \mathrm{~h}^{-1}$ in the non-SH group $(p<0.05)$ and $1.96 \pm 1.97 \mathrm{~h}^{-1}$ $(p>0.05)$ in the SH-group, respectively. Corresponding $k$-values for glucose appearance were $0.51 \pm 0.11 \mathrm{~h}^{-1}$, $0.67 \pm 0.15 \mathrm{~h}^{-1}(p<0.05)$ and $0.73 \pm 0.37 \mathrm{~h}^{-1}(p>0.05)$, respectively. A significant correlation between these two parameters was demonstrable in the $\mathrm{SH}$-group $(r=0.80, p<0.01)$ but not in the non-SH-group $(r=0.06)$ or in healthy subjects $(r=0.25)$ (Fig. 2).

The values of blood glucose and counter-regulatory hormones in the patients at nadir hypoglycaemia in the SH-group are illustrated in Table 3. Clear-cut responses of glucagon were demonstrable in three patients (nos.3, 6 and 9), while virtually no responses at all were registered in five (nos. 1, 5, 10,12, and 14), in spite of the fact that all these subjects were unable to withstand the insulin-infusion test. In three patients (nos.1, 4 and 11), neither adrenaline nor glucagon responses could be registered in the blood glucose range of $1.7-1.8 \mathrm{mmol} / 1$.

In comparing the hormonal responses of the three groups, we chose the circulating levels of counter-regulatory hormones registered when the blood glucose was closest to $2.4 \mathrm{mmol} / \mathrm{l}$, which corresponded to the mean, nadir, blood-glucose level of the healthy subjects (Fig.3). A subnormal response of glucagon $(p<0.02)$ 

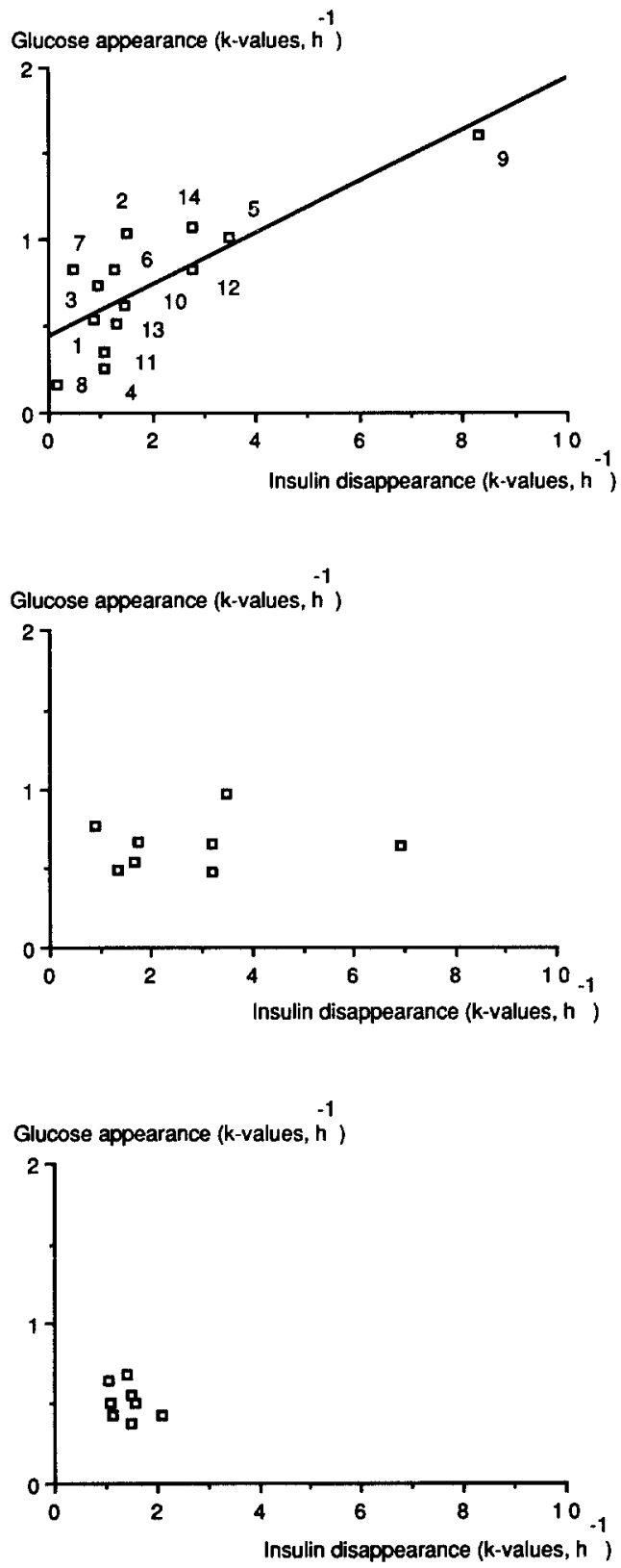

Fig.2. Individual $k$-values for glucose appearance and insulin disappearance during $60 \mathrm{~min}$ after cessation of insulin infusion. Upper panel denotes diabetic patients with severe hypoglycaemia $(n=14)$, middle panel diabetic patients without severe hypoglycaemia $(n=8)$ and lower panel healthy subjects $(n=8)$. Numerals indicate individual patients in accordance with Table 1

was seen in the non-SH group while the responses of adrenaline, cortisol and growth hormone were normal. Concerning the SH-group, our patient with abnormal metabolism of insulin (no.8), as well as the two patients who obtained steady state blood glucose values within the normal range, exhibited normal adrenaline, growth hormone and cortisol responses. The hormonal responses of the remaining patients of the SH-group are given in Figure 3. Compared to healthy subjects, adrenaline and glucagon responses were significantly lower $(p<0.02)$ while cortisol and growth hormone were simi- lar $(p>0.05)$. In comparison with the non-SH group, these responses revealed no differences $(p>0.05)$ as to glucagon, cortisol and growth hormone. The response of adrenaline was significantly lower $(p<0.02)$. When the hormonal responses of the whole SH-group $(n=14)$ were compared to the non-SH group no significant differences were found, while, in comparison with healthy subjects the glucagon $(p<0.02)$ and adrenaline $(p<0.05)$ responses were reduced.

\section{Discussion}

In the present study, we chose to identify patients with severe hypoglycaemia by the use of a questionnaire, because there is evidence that only approximately $40 \%$ of severe hypoglycaemic events are treated in emergency wards [24]. We defined severe hypoglycaemia as an event which required the help of another person and according to this definition we found that 20 patients (4\%) had experienced recurrent severe hypoglycaemic events during at least three years. Comparative data on the prevalence of recurrent, severe, hypoglycaemic attacks have until now been unavailable. Our figure, however, seems to agree well with that estimated by Gale and presented in a review article on hypoglycaemia by Frier [25].

There are reports in the literature in which no preventable factor precipitating hypoglycaemia could be identified in as many as $38-49 \%$ of the events [26-27]. Although alcohol consumption, excessive and unnecessary injections of insulin [28], sometimes with a suicidal purpose [29], may be more prevalent than previously thought, other reasons for unexplained, severe, hypoglycaemic attacks must be considered. The occurrence of severe hypoglycaemia has been related to long duration of the diabetic disease [30] which is in accordance with the present finding where the mean duration of diabetes was 30 years in the group of patients with severe hypoglycaemia. It is well documented that the glycaemic control, as assessed by $\mathrm{HbA}_{1 \mathrm{c}}$, is correlated with the risk of hypoglycaemia $[26,31]$. $\mathrm{HbA}_{1 \mathrm{c}}$ values ranged from normal to high in our group of patients with severe hypoglycaemia, so that strict metabolic control could not explain the frequent attacks of severe hypoglycaemia. Overtreatment with insulin could increase the risk of severe hypoglycaemia without improving metabolic control, and Potter and co-workers, who found a relationship between insulin dose and severe hypoglycaemia, recommended that insulin should not be given in excess of $0.8 \mathrm{U} \cdot \mathrm{kg}^{-1} \cdot$ day $^{-1}$ for patients over the age of 50 and not in excess of $1.0 \mathrm{U} \cdot \mathrm{kg}^{-1}$. day $^{-1}$ for younger individuals to prevent hypoglycaemia [27]. In our study, no patient was treated with insulin beyond these limits and most of our patients received considerably lower doses. Nilsson and coworkers found that patients who were demanding i.v. glucose or intramuscular glucagon because of severe 


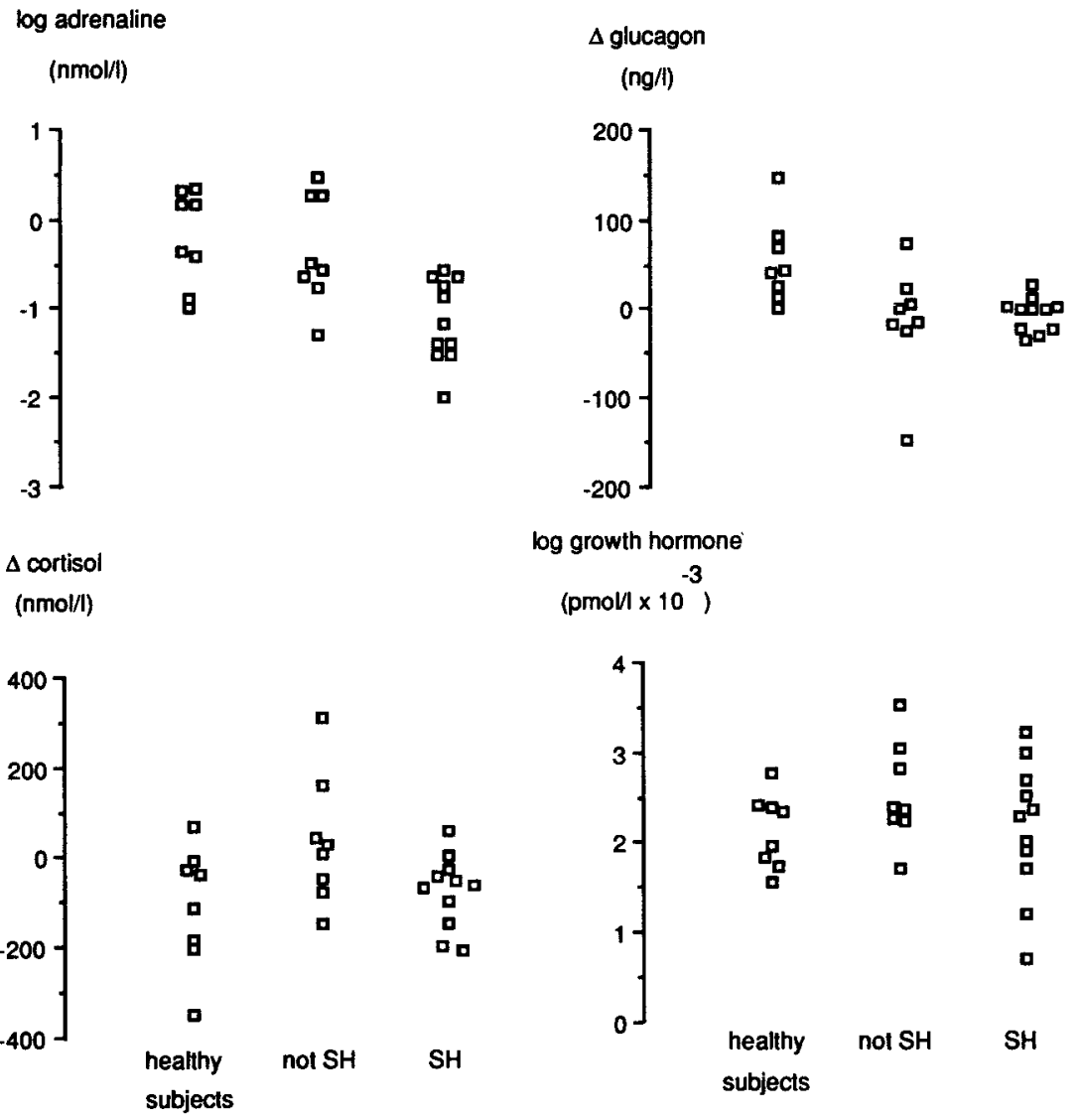

Fig. 3. Plasma levels of counter-regulatory hormones obtained at the blood glucose value closest to $2.4 \mathrm{mmol} / 1$. Adrenaline and growth hormone values are given logarithmically. $\Delta$-values for glucagon and cortisol are calculated as the level at blood glucose closest to $2.4 \mathrm{mmol} / 1$ minus the level at the start of the insulin infusion test. $\mathrm{SH}=11$ patients with severe hypoglycaemia and impaired glucose counter-regulation (two patients with normal glucose counter-regulation and one patient with abnormal metabolism of insulin have been excluded), not $\mathrm{SH}=8$ patients without severe hypoglycaemia hypoglycaemia were treated with less short-acting insulin compared to a matched group (25 vs 39\%) [1]. Although our patients with severe hypoglycaemia were treated with significantly less short-acting insulin than patients without this problem, it should be noticed that our patients with severe hypoglycaemia were prescribed as much as $37 \%$ of their daily insulin dose as short-acting insulin. Therefore, we do not regard overtreatment with insulin or inappropriate insulin regimens as likely factors explaining the severe hypoglycaemic events reported by this group of patients.

Disappearance of insulin is slower in patients with insulin-binding antibodies, and recovery from insulininduced hypoglycaemia is delayed [9]. However, if insulin-antibody-binding is below $10 \%$, insulin metabolism is not believed to be markedly affected [12]. In the present study, antibody-bound insulin above $10 \%$ was registered in as many as eight of the 22 diabetic patients who were exposed to insulin-induced hypoglycaemia, but we found only one patient who presented a MCR of insulin below the -2 SD of the healthy subjects and in whom we believe that interference of insulin-binding antibodies with circulating insulin was of importance for the occurrence of recurrent hypoglycaemia. She was unable to restore her blood glucose after cessation of the insulin infusion. This patient had an antibody titre as high as $64 \%$ according to our assay system. Since another two patients included in this study had insulinbinding to antibodies of the same magnitude, it may be speculated upon whether her antibodies had unique characteristics vis-à-vis binding of insulin.

It is well known that the glucagon release in response to hypoglycaemia may be blunted in diabetic patients $[3,9]$. This defect appears early in the disease whereafter it persists. In the present study, the two diabetic groups displayed similarly reduced glucagon responses at a blood glucose level of $2.4 \mathrm{mmol} / 1$. Interestingly, in three of the patients with impaired glucose counter-regulation, an impressive increment in plasma glucagon could be registered but only at extremely low blood glucose values. Therefore, a preserved adrenaline response appears to be a prerequisite for an adequate counter-regulation of insulin induced hypoglycaemia. The present study as well as several previous reports $[9-11,25]$ have demonstrated a normal adrenaline response in most patients with diabetes mellitus. However, in patients with recurrent and severe episodes of hypoglycaemia, our research team were among the first to present data on the combined failure to raise circulating glucagon and adrenaline during hypoglycaemia [10, 32]. Similar observations have been made by other groups $[8-9,11]$. The prevalence of this adrenomedullary unresponsiveness in diabetic patients with recurrent severe hypoglycaemia has so far not been documented. In the present study we had the possibility to expose 14 such patients to a standardized insulin-infusion test. Twelve of these patients were unable to counteract the effect of insulin for the $3-\mathrm{h}$ period and 
11 patients had significantly impaired adrenaline and glucagon responses, as compared with healthy subjects. Thus, of the investigated patients with recurrent and severe hypoglycaemic episodes, as many as 70\% demonstrated this abnormality. Our findings in the present investigation indicate, that impaired hormonal responses to hypoglycaemia are important in explaining why patients repeatedly develop severe hypoglycaemia. In two patients with recurrent severe hypoglycaemia the insulin-infusion test did not disclose any obvious abnormalities. The mechanism precipitating severe hypoglycaemia in these two patients remains unrevealed.

The validity of the insulin-infusion test in identifying patients with impaired counter-regulation of hypoglycaemia has been questioned by Polonsky and coworkers [33] who were unable to demonstrate a correlation between counter-regulatory hormone responses and susceptibility to severe hypoglycaemia. However, the patients in their study had experienced recurrent hypoglycaemic comas for a period not longer than six months and, therefore, they probably failed to identify a group of patients particularly prone to developing repeated and severe hypoglycaemic events. In 1983, White and co-workers demonstrated that patients with inadequate counter-regulation during an insulininfusion test were more susceptible to severe hypoglycaemia when their insulin therapy was intensified [34], which has also been shown by Bolli et al. [35]. Taken together, the above mentioned studies by White et al. and Bolli et al. and our present study demonstrate a relationship between susceptibility to recurrent and severe hypoglycaemic episodes and the inadequate counter-regulation of a standardized, insulin-infusion test. Furthermore, diabetic patients with an impaired hormone response to hypoglycaemia appear to be susceptible to the inappropriate pharmacokinetics of circulating insulin induced by circulating insulin-binding antibodies since a significant correlation was found between the appearance of blood glucose and the disappearance of plasma insulin after cessation of the insulin infusion in the patients with severe hypoglycaemia only. Thus, in patients with impaired hormonal responses to insulin-induced hypoglycaemia and raised levels of insulin binding to antibodies, it is attractive to think that the delayed elimination of insulin from the circulation may be of importance in prolonging hypoglycaemia.

In conclusion, recurrent episodes of severe hypoglycaemia occurred in about $4 \%$ of our insulin-treated diabetic patients. In approximately $70 \%$ of our patients with recurrent attacks of severe hypoglycaemia, a combined deficiency of glucagon and adrenaline was documented, and was believed to be the likely cause of their inclination for hypoglycaemia. Under such circumstances the disappearance of insulin is critical for the recovery of blood glucose after hypoglycaemia. A standardized, insulin-infusion test may be helpful for identifying patients with impaired counter-regulation to hypoglycaemia.
Acknowledgements. We are grateful to Prof. S. Efendic, Prof. B. Hamberger and Assistant Prof. T. Curstedt for hormone analyses. We are also grateful to Miss A. Ekelund for skillful technical assistance. This work was supported by grants from the Nordic Insulin Foundation, the NOVO Company A/S, Denmark, the Swedish Diabetic Association, the Swedish Medical Research Council (Grant No.19x-6589), the "Förenade Liv" Mutual Group Life Insurance Company, Stockholm, Sweden, and the Karolinska Institute.

\section{References}

1. Nilsson A, Tideholm B, Kalén J, Katzman P (1988) Incidence of severe hypoglycemia and its causes in insulin-treated diabetics. Acta Med Scand 224: 257-262

2. The DCCT Research Group (1986) The Diabetes Control and Complications Trial (DCCT): design and methodologic considerations for the feasibility phase. Diabetes $35: 530-545$

3. Gerich JE, Campbell PJ (1988) Overview of counterregulation and its abnormalities in diabetes mellitus and other conditions. Diabetes Metab Rev 4: 93-111

4. Olson LD, Winternitz WW (1977) Hypopituitarism: a complication of diabetes. South Med J 70: 411-413

5. McMahon M, Gerich J, Rizza R (1988) Effects of glucocorticoids on carbohydrate metabolism. Diabetes Metab Rev 4: 17-30

6. Hermansen K, Johannsen LG, Rasmussen OB (1985) Hypoglycaemic coma in severe primary hypothyroidism. Acta Med Scand 218: $345-346$

7. Clausen N, Lins P-E, Adamson U, Hamberger B, Efendić S (1986) Counterregulation of insulin-induced hypoglycaemia in primary hypothyroidism. Acta Endocrinol 111: 516-521

8. Boden G, Reichard GA, Hoeldtke RD, Rezvani I, Owen OE (1981) Severe insulin-induced hypoglycemia associated with deficiencies in the release of counterregulatory hormones. $\mathbf{N}$ Engl $\mathbf{J}$ Med 305: 1200-1205

9. Bolli GB, de Feo P, Compagnucci P, Cartechini MG, Angeletti G, Santeusanio F, Brunetti P, Gerich JE (1983) Abnormal glucose counterregulation in insulin-dependent diabetes mellitus. Diabetes 32: 134-141

10. Adamson U, Lins P-E, Efendić S, Hamberger B, Wajngot A (1984) Impaired counterregulation of hypoglycemia in a group of insulin-dependent diabetics with recurrent episodes of severe hypoglycemia. Acta Med Scand 216: 215-222

11. Santiago JV, White NH, Skor DA, Levandoski LA, Bier DM, Cryer PE (1984) Defective glucose counterregulation limits intensive therapy of diabetes mellitus. Am J Physiol 247: E 215-220

12. Madsbad S, Hilsted J, Krarup T, Sestoft L, Christensen NJ, Tronier B (1985) The importance of plasma free insulin and counterregulatory hormones for the recovery of blood glucose following hypoglycaemia in type 1 diabetics. Acta Endocrinol 108: 224-230

13. Van Haeften TW, Bolli GB, Dimitriadis GD, Gottesman IS, Horwitz DL, Gerich JE (1986) Effect of insulin antibodies and their kinetic characteristics on plasma free insulin dynamics in patients with diabetes mellitus. Metabolism 35: 649-656

14. Wredling R, Adamson U, Lins P-E (1988) Prevalence and clinical significance of anti-insulin antibodies during insulin therapy. Acta Endocrinol 118 [Suppl 289]: 39 (Abstract)

15. Angelone A, Coulter NA (1964) Respiratory sinus arrhythmia: a frequency dependent phenomenon. J Appl Physiol 19: 479-482

16. Page MM, Watkins PJ (1978) Cardiorespiratory arrest and diabetic autonomic neuropathy. Lancet I: 14-16

17. Jeppson JO, Jerntorp P, Sundkvist G, Englund H, Nylund V (1986) Measurement of hemoglobin A1c by a new liquid-chromatographic assay: methodology, clinical utility and relation to glucose tolerance evaluated. Clin Chem 32: 1867-1872

18. Nakagawa S, Nakayama H, Sasaki T, Yoshino K, Yu YY, Shinozaki K, Aoki S, Mashimo K (1973) A simple method for the determination of serum free insulin levels in insulin-treated patients. Diabetes 22: 590-600 
19. Heding LG (1975) Radioimmunological determination of human C-peptide in serum. Diabetologia 11: 541-548

20. Faloona GR, Unger RH (1974) Glucagon. In: Jaffe BM, Behrman HR (eds) Methods of hormone radioimmunoassay. Academic Press, New York London, pp 317-330

21. Cerasi E, Della Casa L, Luft R, Roovete A (1966) Determination of human growth hormone (HGH) in plasma by a double antibody radioimmunoassay. Acta Endocrinol 53:101-120

22. Lantto O, Lindbäck B, Aakvaag A, Damkjaer-Nielsen M, Pomoell U-M, Björkhem I (1983) Assay of cortisol with a radioimmunoassay method calibrated by isotope dilution-mass spectrometry. A Nordic collaborative study. Scand J Clin Lab Invest 43: 433-437

23. Hallman H, Farnebo L-O, Hamberger B, Jonsson G (1978) A sensitive method for the determination of plasma catecholamines using liquid chromatography with electrochemical detection. Life Sci 23: 1049-1052

24. Casparie AF, Elving LD (1985) Severe hypoglycemia in diabetic patients: frequency, causes, prevention. Diabetes Care 8: 141-145

25. Frier BM (1986) Hypoglycaemia and diabetes. Diabet Med 3: 513-525

26. Moses RG, Hubert PA, Lewis-Driver DJ (1985) Severe hypoglycaemia. A one-year prospective survey in Wollongong. Med $\mathbf{J}$ Austr 142: 294-296

27. Potter J, Clarke P, Gale EA, Dave SH, Tattersall RB (1982) Insulin-induced hypoglycaemia in an accident and emergency department: the tip of an iceberg? Br Med J 285: 1180-1182

28. Schade DS (1988) Brittle diabetes: Strategies, diagnosis, and treatment. Diabetes Metab Rev 4: 371-390

29. Arem R, Zoghbi W (1985) Insulin overdose in eight patients: insulin pharmacokinetics and review of the literature. Medicine (Baltimore) 64: 323-332
30. Goldgewicht C, Slama G, Papoz L, Tchobroutsky G (1983) Hypoglycaemic reactions in 172 Type 1 (insulin-dependent) diabetic patients. Diabetologia 24: 95-99

31. Goldstein DE, England JD, Hess R, Rawlings SS, Walker B (1981) A prospective study of symptomatic hypoglycemia in young diabetic patients. Diabetes Care 4: 601-605

32. Adamson U, Efendić S, Lins PE, Wajngot A (1980) Lack of epinephrine response to hypoglycaemia in diabetics with repeated hypoglycaemic comas. Diabetologia 19: 251 (Abstract)

33. Polonsky K, Bergenstal R, Pons G, Schneider M, Jaspan J, Rubenstein A (1982) Relation of counterregulatory responses to hypoglycemia in type I diabetics. N Engl J Med 307: 1106-1112

34. White NH, Skor DA, Cryer PE, Levandoski LA, Bier DM, Santiago JV (1983) Identification of type I diabetic patients at increased risk for hypoglycemia during intensive therapy. $N$ Engl J Med 308: 485-491

35. Bolli GB, De Feo P, De Cosmo S, Perriello G, Ventura MM, Massi Benedetti M, Santeusanio F, Gerich JE, Brunetti P (1984) A reliable and reproducible test for adequate glucose counterregulation in type I diabetes mellitus. Diabetes 33: 732-737

Received: 7 February 1989

and in final revised form: 7 August 1989

Dr. N.Clausen Sjöbom

Department of Internal Medicine

Danderyd Hospital

S-182 88 Danderyd

Sweden 